\title{
HAMZAH \{\} PREFIXANDGEMINATION $\{\because\} O F F I ' L$ TSULATSY MAZID IN ARABIC: CASE STUDY FROM SURAH AL BAQARAH
}

\author{
Khoirin Nikmah ${ }^{1}$ \\ Universitas Muhammadiyah Yogyakarta ${ }^{1}$ \\ Khoirinikmah23@gmail.com
}

\begin{abstract}
This research focused on hamzah \{\}\} prefix and gemination $\{-\}$ of fi'l tsulatsy mazid in Arabic: Case study from surah al baqarah. It was aimed to describe: (1)hamzah prefix and gemination of fi'l tsulatsy mazid's distributions from surah al baqarah; (2) meaning from their distributions. The approach applied in this research is descriptivequalitative. Meanwhile, the method of collecting data is observation method with recording andtaking note technique.According to the number of data, there are five formulas found related to prefix hamzah \{\}\} and gemination \{-\}.In this case, hamzah \{\}\} prefixfrom surah al baqarahmight be distributeto verb, noun, adjective, andadverb. Then, gemination\{-\}might be distribute to verb, noun, and adjective. Furthermore, there was one similarity between them. Either hamzah prefix or gemination has benefactive meaning when it was distributed to verb, noun, and also adjective.
\end{abstract}

Keywords: Hamzah prefix, gemination, fi'l tsulatsy mazid, Al Baqarah

\begin{abstract}
Abstrak
Penelitian ini berfokus pada awalan hamzah \{\}\} dan geminasi $\{-\}$ dari fi tsulatsy mazid dalam bahasa Arab: Studi Kasus dari Surat Al Baqarah. Penelitian ini bertujuan untuk menggambarkan (1) awalan hamzah dan geminasi distribusi fi tsulatsy mazid dari Surah Al Baqarah; (2) makna dari distribusi keduanya. Pendekatan yang digunakan dalam penelitian ini ialah deskriptif kualitatif dengan metode observasi dan teknik catat untuk pengumpulan data. Terdapat 5 rumus yang ditemukan terkait dengan awalan hamzah \{\}\} dan geminasi $\{-\}$. Dalam hal ini, awalan hamzah \{'\} dari Surah Al Baqarah mungkin didistribusikan ke dalam kata kerja, kata benda, kata sifat, dan kata keterangan. Kemudian $\{-\}$ mungkin didistribusikan ke dalam kata kerja, kata benda, dan kata sifat. Selanjutnya, terdapat kesamaan di antara keduanya, awalan hamdah atau geminasi memiliki makna yang sama ketika didistribusikan ke dalam kata kerja, kata benda, dan juga kata sifat.
\end{abstract}

Kata kunci: awalan hamzah, geminasi, fi'l tsulatsy mazid, Al Baqarah

submit date: 20-02-2021 accept date: 10-03-2021 publish date: 13-03-2021

Correspondence author: Khorin Nikmah, Yogyakarta, Indonesia. E-Mail: khoirinikmah23@gmail.com

Doi: https://doi.org/10.36929/sigeh\%20elt.v1i1.353

(c) (i) (2)

Journal SIGEH licensed under a Creative Commons Attribution-ShareAlike 4.0 International License.

\section{PENDAHULUAN}

Istilahfi'l tsulatsiymengacu pada tsulatsiymujarrad dan tsulatsiy mazid. Mujarrad

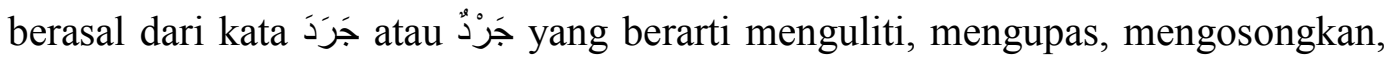
dan melepaskan. Kemudian beralih menjadi مُجَرَّ yan yang berarti kata yang tidak berhuruf tambahan. Dengan demikian, fi'l mujarrad berarti kata kerja yang sepi 
dari huruf tambahan, semua hurufnya adalah asli (Anas, 2007: 9). Adapun contoh dari fi'l tsulatsiy mujarrad seperti pada كََبَ (kataba) 'menulis', ضَرَبَ (dharaba) 'memukul', نَصَر (nashara) 'menolong'. Sementara itu, fi'l mazid adalah fi'l yang memperoleh huruf tambahan, baik satu huruf, dua huruf, ataupun lebih. Seperti

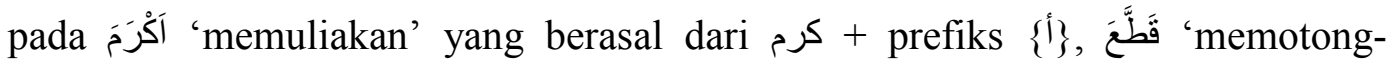

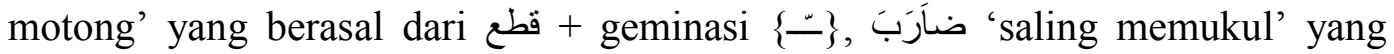
berasal dari ضرب+infiks $\{\mid\}$.

Dalam bahasa Arab, salah satu pembentukan fi'ladalah melalui afiksasi. Hal ini sebagaimana yang termaktub pada Al amtsilah At tashrifiyyah karangan Ma'sum (1965). Bahasa Arab memiliki empat prefiks yang meliputi hamzah \{\} ,

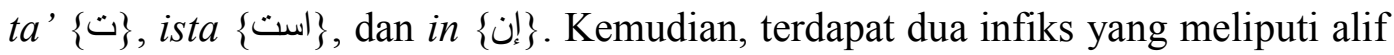
$\{1\}$ dan geminasi atau tasydid $\{\ddot{-}\}$. Adapun konfiks pada bahasa Arab meliputi, kombinasi prefiks $\{ت\}$ dan infiks $\{\mid\}$, kombinasi prefiks $\{\mid\}$ dan infiks $\{ت\}$, kombinasi prefiks $\{!\}$ dan sufiks $\{-\}$, kombinasi prefiks $\{\mid\}$, pengulangan konsonan ke dua, dan infiks $\{g\}$, kombinasi prefiks $\{\mid\}$ dan $\{\dot{U}\}$, serta kombinasi \{! dan sufiks $\{\ddot{-}\}$. Dalam makalah ini, ruang lingkup pembahasan hanyadifokuskan pada distribusi beserta makna prefiks hamzah \{\} dan geminasi $\{-\}$ pada fi'l tsulatsiy mazidyang terdapat dalam Al Quran, khususnya surat al baqarah.

Adapun tujuan penelitian ini adalah sebagai berikut.

a. Untuk mendeskripsikan distribusi prefiks hamzah $\{\{\}$ dan geminasi $\{\ddot{-}\}$ padafi'l tsulatsiy mazid dalam surat al baqarah.

b. Untuk mendeskripsikan makna dari distribusi prefiks hamzah $\{\{\}$ dan geminasi $\{\because$ \} pada fi'l tsulatsiy mazid dalam surat al baqarah.

\section{METODE}

Dalam penelitian, digunakan paling tidak tiga tahapan sebagai berikut. Pertama, pengumpulan data yang diperoleh melalui sumber data primer dan sekunder. Sumber data primerdiperoleh dariAl quran surat al baqarah, adapun sumber data sekunder diperoleh dariKamus Al munawwir Arab-Indonesia. Penjaringan data 
diambil melalui metode simak atau observasi dengan teknik sadap serta teknik catat. Kedua, analisis data. Dalam menganalisis data digunakan metode agih dengan teknik bagi unsur langsung. Dalam hal ini, penelitian dilakukandengan cara membagi dan mengklasifikasikan distribusi fi'l tsulatsiy mazid yang memperoleh prefiks $\{\{\}$ dangeminasi $\{\ddot{-}\}$ dalam bahasa Arab. Ketiga, penyajian hasil analisis data.

\section{HASIL DAN PEMBAHASAN}

\section{Distribusi, Fungsi, dan Makna Prefiks $\{\{\}$}

Dalam bahasa Arab, prefiks hamzah memiliki beragam distribusi. Prefiks hamzah $\{\{\}$ dapat beridstribusi dengan verba, nomina, ajektiva, dan adverbia.Beberapa contoh kata berikut diambil dari Ahya (2013: 22-30). Lebih lanjut, distribusi prefiks hamzah sebagaimana penjabaran berikut.

a. Prefiks $\{\{\}$ yang dilekatkan pada verba seperti yang terdapat pada:

أكرم = 'memuliakan'

أبرأ 'menyembuhkan'

أعطى = 'memberikan'

Prefiks $\{\{\}$ yang dilekatkan pada verba, umumnya berfungsi sebagai verba transitif ( $f$ 'l muta'addi). Oleh karena itu, afiksasi semacam ini berupa infleksi karena tidak mengubah kelas kata. Bentuk dasar verba yang memperoleh prefiks $\{\{\}$, tetap menjadi verba.

b. Prefiks $\{\{\}$ yang dilekatkan pada nomina seperti yang terdapat pada:

'أحجز 'menuju ke Hijaz'

أورق = 'berdaun'

ثمر + أثمر 'berbuah'

Pada contoh di atas, prefiks $\{\{\}$ yang dilekatkan pada nomina mengandung dua makna, 'menuju' dan 'mengeluarkan'. Ketika nomina tersebut berupa nama sebuah tempat, maka afiksasi mengakibatkan ia bermakna 'menuju'. Dalam hal ini, proses morfemis berupa infleksi karena nomina tidak mengalami perubahan kata, hanya saja memperoleh verba tambahan. 'Hijaz’ menjadi ‘menuju ke Hijaz’ Di sisi lain, nomina tersebut dapat juga 
bermakna 'mengeluarkan', yakni mengeluarkan atau memunculkan verba dari nomina. Misalnya, 'daun' menjadi 'berdaun', 'buah' menjadi 'berbuah'. Berkaitan dengan hal ini, terjadi proses morfemis berupa derivasi karena afiksasi mengakibatkan terjadinya perubahan kelas kata. Nomina menjadi verba.

c. Prefiks $\{\{\}$ yang dilekatkan pada ajektiva seperti yang terdapat pada:

أفقر = 'menjadi fakir'

أعظم = 'mengagungkan'

Berdasarkan contoh di atas, ketika prefiks $\{\{\}$ dilekatkan pada ajektiva, maka mengandung dua makna. Pertama, bermakna kausatif 'menjadi', dalam hal ini proses morfemis berupa infleksi karena tidak mengubah kelas kata ajektiva. Kedua, bermakna 'menunjukkan sifat pada sesuatu', dalam hal ini proses morfemis berupa derivasi karena mengubah kelas kata dari ajektiva menjadi verba.

d. Prefiks $\{\{\}$ yang dilekatkan pada adverbia seperti yang terdapat pada:

'berada/memasuki waktu sore'

أصن = 'berada/memasuki waktu pagi'

Berdasarkan contoh di atas, prefiks hamzah yang dilekatkan pada adverbial mengandung makna 'menyatakan hal atau keadaan'. Dalam hal ini, proses morfologis berupa derivasi.

\begin{tabular}{|c|c|c|c|c|}
\hline No. & Verba dasar & Makna & Afiksasi & Makna \\
\hline 1. & نزل & Turun & أنزل =نزل + أ & Menurunkan \\
\hline 2. & خرج(Kharaja) & Keluar & أخرج = خرج + أ & Mengeluarkan \\
\hline 3. & نجّى & Menyelamatkan & أنجى = نجّى + أ & Menyelamatkan \\
\hline 4. & (Gharaqa) & Tenggelam & أغرق = غرق + أ & Menenggelamkan \\
\hline 5. & قرار(Qarār) & Keputusan, ikrar & أقرر = قرار + أ & Berikrar \\
\hline 6. & صلح)(shulhun) & Perdamaian & أصلح =صلح + أ & Mendamaikan \\
\hline 7. & سلم & $\begin{array}{l}\text { Selamat, agama } \\
\text { islam }\end{array}$ & أسلم = سلم + أ & $\begin{array}{l}\text { Tunduk (Masuk } \\
\text { islam ) }\end{array}$ \\
\hline 8. & 華(tamma) & Selesai & أنّّ = تُّ + أَّ & $\begin{array}{l}\text { Menunaikan } \\
\text { (menyelesaikan) }\end{array}$ \\
\hline 9. & شدّ (Syaddun) & Sangat & أشثدّ = شدّد أ & Sangatlah \\
\hline 10. & (Hubb) حبّ (Hub & Cinta, suka & أحبّ = حبّ + أ & Menyukai \\
\hline 11. & نفقة (Nafaqah) & Tunjangan, biaya & أنفق = نفق + أ & Menafkahkan harta \\
\hline 12. & خطأ (Khata') & Salah & أخطأ = خطأ + أ & Tersalah (bersalah) \\
\hline
\end{tabular}


Adapunfil'-fi'l yang diperoleh dari Al quran suratal baqarah adalah sebagai berikut.

Pada poin (1), (2), (3), dan (4) kata anzala, akhraja, anjā, dan aghraqa berasal dari kata dasar berupa verba yang memperoleh prefiks $\{\{\}$ sehingga menghasilkan verba transitif atau fi'l muta'addi dengan makna benefaktif. Dalam hal ini, proses morfologis berupa derivasi. Prefiks \{\}$\}+\mathbf{V}=\mathbf{V t r a n s} \rightarrow$

\section{Benefaktif.}

Pada poin (5) dan (12) terjadi proses morfologis berupa derivasi. Verba aqrara 'berikrar' berasal dari nomina qarār 'keputusan, ikrar'. Adapun Verba akhta'a 'tersalah/bersalah' berasal dari nomina khata'a 'salah'. Nomina-nomina tersebut memperoleh prefiks $\{\{\}$ sehingga mengubah kelas kata menjadi verba instransitif dengan makna yang memunculkan nomina. Prefiks \{\}$\}+\mathbf{N}=$ Vintrans $\rightarrow$ Memunculkan nomina.

Pada poin (6), (8), dan (11) terjadi proses morfologis berupa derivasi. Verbaashlaha 'mendamaikan' berasal dari nomina shulhun 'perdamaian'. Verba atamma 'menunaikan/menyelesaikan' berasal dari nomina tamma 'selesai', adapun verba anfaqa 'menafkahan harta' berasal dari nomina nafaqah'tunjangan, biaya'. Nomina-nomina tersebut memperoleh prefiks $\{\{\}$ sehingga mengubah kelas kata menjadi verba transitif dengan makna benefaktif. Prefiks \{\}$\}+\mathbf{N}=$ Vtrans $\rightarrow$ Benefaktif.

Pada poin (7) terjadi proses morfolgis berupa derivasi.Verba aslama 'tunduk, masuk islam' berasal dari kata dasar berupa nomina salama 'selamat, agama islam'. Nomina tersebut memperoleh prefiks $\{\{\}$ sehingga mengubah kelas kata menjadi verba dengan makna kausatif (menjadi), dalam hal ini menjadi masuk islam. Prefiks $\{\{\}+\mathbf{N}=$ Vtrans $\rightarrow$ Kausatif.

Pada poin (9) terjadi proses morfologis berupa infleksi. Adverbia syaddun 'sangat' ketika memperoleh prefiks \{\}$\}$ tidak mengalamiperubahan kelas kata. Namun, terjadi perubahan adverbial yang bemakna melebih-lebihkan. Dalam bahasa Arab, fenomena ini disebut dengan isim tafdhil, yaitu penambahan prefiks 
hamzah yang berfungsi untuk membentuk hiperbola. Prefiks $\{\{\}+$ Adv $=$ Adv $\rightarrow$ Hiperbola.

Pada poin (10) terjadi proses morfologis berupa derivasi. Verba ahabba 'menyukai' berasal dari ajektiva hubb 'cinta, suka'. Ajektiva tersebut memperoleh prefiks $\{\{\}$ sehingga mengubah kelas kata menjadi verba transitif yang bermakna benefaktif. Prefiks $\{\{\}+$ Adj $=$ Vtrans $\rightarrow$ Benefaktif.

Berdasarkan penjabaran di atas, dapat diformulasikansebagai berikut.

1) Prefiks $\{\{\}+V=$ Vtrans $\rightarrow$ Benefaktif

2) Prefiks $\{\{\}+\mathrm{N}=$ Vintrans $\rightarrow$ Memunculkan nomina

3) Prefiks $\{\{\}+\mathrm{N}=$ Vtrans $\rightarrow$ Benefaktif

4) Prefiks $\{\{\}+\mathrm{N}=$ Vtrans $\rightarrow$ Kausatif

5) Prefiks $\{\{\}+\operatorname{Adv}=\operatorname{Adv} \rightarrow$ Hiperbola

6) Prefiks $\{\{\}+$ Adj $=$ Vtrans $\rightarrow$ Benefaktif

Sehingga:

1. Jika Pre $\{\{\}+((V)(N)($ Adj $))=$ Vtrans, maka $>$ Pre $\{\{\}+((V)(N)($ Adj $))=$ Benefaktif

2. Pre $\{\{\}+\mathrm{N}=\mathrm{V}>(($ Vtrans [Benefaktif] [Kausatif] $)$ (Vintrans)) Pre $\{1\}$
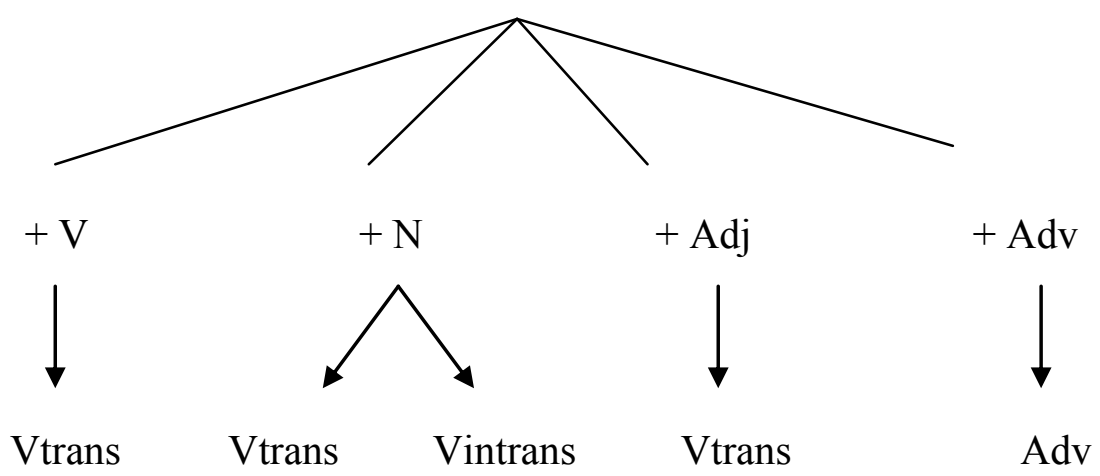

\section{Distribusi, Fungsi, dan Makna Geminasi $\{\because\}$}

Geminasi dapat didistribusikan pada verba, nomina, dan ajektiva. Distribusi yang berbeda tidak menutup kemungkinan menghasilkan makna yang sama. Berikut ini contoh distribusi geminasi.

a. Geminasi pada Verba 


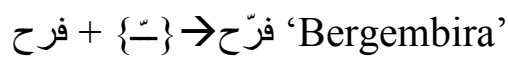

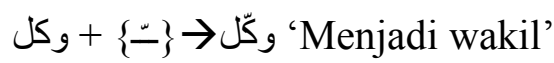

لقيّى 'Bertemu'

Proses morfologis di atas berupa infleksi. Farraha 'bergembira' menunjukkan verba intransitif. Wakkala 'menjadi wakil' mengandung makna verba kausatif. Adapun laqqā 'bertemu' mengandung makna verba benefaktif.

b. Geminasi pada Nomina

خيّم خ 'Mendirikan tenda/ berkemah'

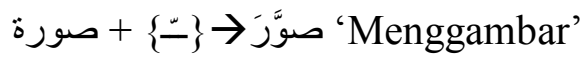

Dalam hal ini terjadi proses morfologis berupa derivasi, yakni perubahan nomina menjadi verba. Khaimah 'tenda' ketika digeminasikan berubah menjadi khayyama 'berkemah', sementara itu, sūrah 'gambar' ketika digeminasikan berubah menjadi shawwara 'menggambar'. Kaitannya dengan maknanya, perubahan nomina menjadi verba pada geminasi berfungsi untuk mengambil kata kerja dari isim 'nomina'.

\begin{tabular}{|c|c|c|c|c|}
\hline No. & $\begin{array}{l}\text { Verba } \\
\text { Dasar }\end{array}$ & Makna & Geminasi & Makna \\
\hline 1. & 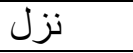 & Turun & نَزَّلَ & Mewahyukan \\
\hline 2. & 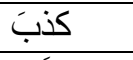 & Bohong & 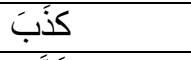 & Mendustakan \\
\hline 3. & نَجَا & Selamat & نَجَّى & Menyelamatkan \\
\hline 4. & ذَنَعَ & Menyembelih & 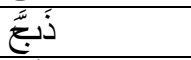 & Menyembelih \\
\hline 5. & بَانَ & Terang, jelas & بَيَّنَ & Menerangkan \\
\hline 6. & شَقَ & Membelah & شَقِق & Terbelah \\
\hline 7. & عَرَفْ & Membelokkan & عَرَّفَ & Mengubah \\
\hline 8. & 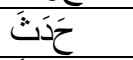 & Terjadi & (حَدَثَنَ & Menceritakan \\
\hline 9. & خَفْةَ & Ringan & خَفَفْ & Diringankan (Meringankan) \\
\hline 10. & وصية & Pesan, wasiat & وَصَّى & Mewasiatkan \\
\hline 11. & 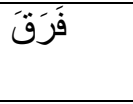 & $\begin{array}{l}\text { Memisahkan, } \\
\text { membedakan }\end{array}$ & فَرَّقُ & Membedakan \\
\hline 12. & علم & Pengetahuan & عَلْمَ & Mengajarkan \\
\hline 13. & بِشِر & Kegembiraan & بشٌر & Memberikan berita gembira \\
\hline 14. & (حُرَمَ & Haram & عَرَّنَ & Mengharamkan \\
\hline 15. & كلام & $\begin{array}{l}\text { Pembicaraan, } \\
\text { perkataan }\end{array}$ & كَّلَّمَ & Berbicara kepada \\
\hline 16. & بَبَلَّلَ & Mengubah & 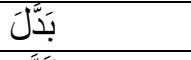 & Mengubah \\
\hline 17. & كَبْرَ & Besar & كَبَرَ & Mengagungkan \\
\hline
\end{tabular}




\begin{tabular}{|c|c|c|c|c|}
\hline 18. & حبَّ & Cinta & يجبَّ & Menyukai \\
\hline 19. & زَانَ & Menghiasi & زَيَيَنَ & $\begin{array}{l}\text { Dijadikan indah } \\
\text { (Menjadikan indah) }\end{array}$ \\
\hline 20. & طَلْق & Melepas ikatan & طَلْق & Mentalak \\
\hline 21. & سَرَحَ & Melepaskan & سَرَّحَ & Menceraikan \\
\hline 22. & كَفر & Menutupi & كَفْرَ & Menyembunyikan \\
\hline & حَملَ & Memikul & حَمّلَ & Memikulkan \\
\hline
\end{tabular}

c. Geminasi pada Ajektiva

يسّر بـ 'Mempermudah'

قوى 'Menguatkan’

أدّب ‘ُ 'Mendidik'

Hal yang sama juga berlaku ketika geminasi berasal dari ajektiva, terjadi derivasi menjadi verba. Yasara 'mudah' ketika digeminasikan menjadi yassara 'mempermudah'. Qawā 'kuat' ketika digeminasikan berubah menjadi qawwā 'menguatkan'. Adapun aduba 'sopan' ketika digeminasikan berubah menjadi addaba 'mendidik'. Pada kata yassara dan qawwā, makna geminasi berfungsi untuk menjadikan benefaktif, sementara itu, pada kata addaba berfungsi untuk menisbatkan maf'ul bih (objek) kepada asal kata kerjanya.

Berikut ini hasil identifikasifi'l yang diperoleh dari Al quran surat al baqarah.

Poin (1), (3), dan (23) mengalami proses morfologis berupa infleksi. Ketika verba-verba tersebut digeminasikan, maka menghasilkan verba transitif. Nazala 'turun' menjadi nazzala 'menurunkan (mewahyukan)', Najā 'selamat' menjadi najjā 'menyelamatkan', dan hamala 'memikul' menjadi hammala 'memikulkan'. $\mathbf{V}+\{\ddot{-}\}=$ Vtrans $\rightarrow$ Makna benefaktif.

Poin (2), (5), (9), (14), dan (17) merupakan ajektiva yang mengalami derivasi. sehingga ajektiva tersebut berubah menjadi verba transitif ketika digeminasikan. Kadzaba 'bohong/dusta' menjadi kadzzaba 'mendustakan', bāna 'terang/jelas' menjadi bayyana 'menerangkan', khaffa 'ringan' mejadi khaffafa 'meringankan', hurima 'haram' menjadi harrama 'mengharamkan', kabura 'besar' menjadi kabbara 'mengagungkan'. Adj $+\{\ddot{-}\}=$ Vtrans $\rightarrow$ Makna benefaktif. 
Poin (4), (11), dan (16) merupakan verba-verba yang ketika digeminasikan tidak mengalami perubahan kelas kata maupun makna. Nabaha dan nabbaha bermakna 'menyembelih', faraqa dan farraqa bermakna 'membedakan', badala dan baddala bermakna 'mengubah'. $\mathbf{V}+\{\ddot{-}\}=$ Vasli.

Poin (6) merupakan verba yang bermakna tindakan yang disengaja. Ketika digeminasikan, verba tersebut berubah makna menjadi tindakan yang tidak disengaja. Syaqqa 'membelah' menjadi syaqqaqa 'terbelah'. Vsengaja $+\{\ddot{-}\}=$ Vtidak sengaja.

Poin (7) dan (8) merupakan verba yang ketika digeminasikan mengalami perubahan menjadi verba transitif. Verba transitif tersebut mengandung makna berupa penisbatan maf'ul bih (objek) kepada asal kata kerjanya. Harafa 'membelokkan' menjadi harrafa 'mengubah (mengubah arah)', hadasta 'terjadi' menjadi haddatsa 'menceritakan (menceritakan kejadian)'. $\mathbf{V}+\{\ddot{-}\}=\mathbf{V t r a n s} \rightarrow$ menisbatkan maf'ul bih (objek) kepada asal kata kerja.

Poin (10), (15), dan (18) merupakan nomina yang mengalami derivasi. Ketika digeminasikan berubah menjadi verba transitif yang bermakna benefaktif. Wasiyah 'wasiat' menjadi wassha 'mewasiatkan', kalām 'pembicaraan' menjadi kallama 'berbicara kepada', dan hubb 'cinta/suka' menjadi yuhibbu 'menyukai'. $\mathbf{N}+\{\because\}=$ Vtrans $\rightarrow$ Makna benefaktif.

Poin (19), (20), (21), dan (22) merupakan verba yang ketika digeminasikan tidak mengalami perubahan kelas kata, hanya saja menjadi verba yang bersinonim dengan makna yang berasal dari objek kata kerjanya. Zāna 'menghiasi' menjadi zayyana 'menjadikan indah', talaqa 'melepas ikatan' menjadi tallaqa 'mentalak', saraha 'melepaskan' menjadi sarraha 'menceraikan', dan kafara 'menutupi' menjadi kaffara 'menyembunyikan'. $\mathbf{V}+\{\ddot{-}\}=$ Vsin $\rightarrow$ mencabut asal kata

\section{kerja dari objek.}

Poin (12) dan (14) merupakan nomina yang mengalami derivasi. Ketika digeminasikan nomina-nomina tersebut berubah menjadi verba dengan makna yang berasal dari objek kata kerjanya. 'Ilmun 'pengetahuan' menjadi 'allama 'mengajarkan' dan hurima 'haram' menjadi harrama 'mengharamkan'.

\section{$\mathbf{N}+\{\ddot{-}\}=$ Vtrans $\rightarrow$ mencabut asal kata kerja dari objek.}


Berdasarkan penjabaran di atas, maka dapat diformulasikan sebagai berikut.

1) $\mathrm{V}+\{\ddot{-}\}=$ Vtrans $\rightarrow$ Makna benefaktif

2) $\operatorname{Adj}+\{\ddot{-}\}=$ Vtrans $\rightarrow$ Makna benefaktif

3) $\mathrm{V}+\{\ddot{-}\}=$ Vasli

4) Vsengaja $+\{\ddot{-}\}=$ Vtidak sengaja (Vts)

5) $\mathrm{V}+\{\ddot{-}\}=$ Vtrans $\rightarrow$ menisbatkan maf'ul bih (objek) kepada asal kata kerja

6) $\mathrm{N}+\{\ddot{-}\}=$ Vtrans $\rightarrow$ Makna benefaktif

7) $\mathrm{V}+\{\ddot{-}\}=$ Vsin $\rightarrow$ mencabut asal kata kerja dari objek.

8) $\mathrm{N}+\{\ddot{-}\}=$ Vtrans $\rightarrow$ mencabut asal kata kerja dari objek.

Sehingga:

1. Jika $\{\ddot{-}\}+((\mathrm{V})(\mathrm{N})($ Adj $))=$ Vtrans, maka $>\{\ddot{-}\}+((\mathrm{V})(\mathrm{N})($ Adj $))=$ Benefaktif

2. $\{\ddot{-}\}+((\mathrm{V})(\mathrm{N})(\mathrm{Adj}))=\mathrm{V}$

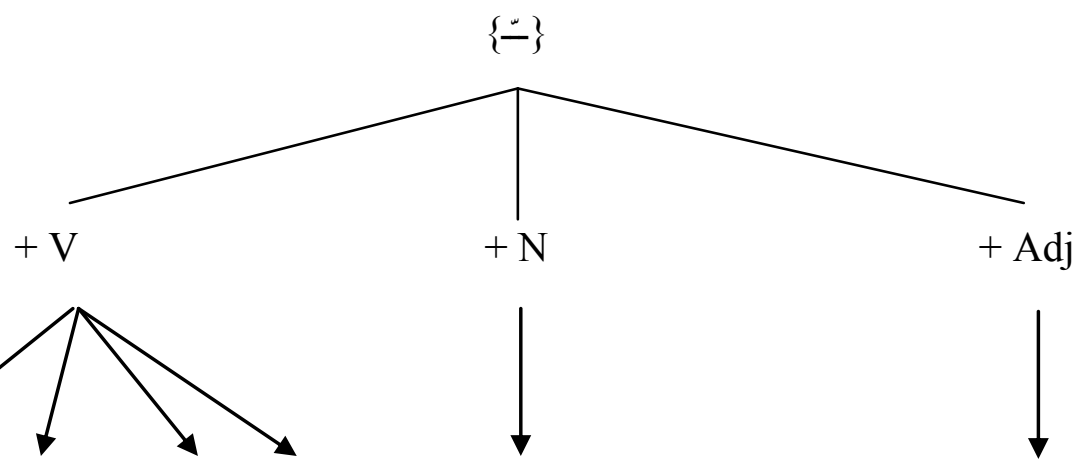

Vtrans Vasli Vts Vsin Vtrans

\section{KESIMPULAN}

Berdasarkan hasil analisis di atas, prefiks hamzah $\{\{\}$ pada Al quran surat Al baqarah dapat berdistribusi dengan verba, nomina, ajektiva, dan adverbia. Adapun geminasi $\{\ddot{-}\}$ dapat didistribusikan dengan verba, nomina, dan ajektiva. Berikut ini kaidah yang diperoleh. 
1) Jika Pre $\{\{\}+((V)(N)($ Adj $))=$ Vtrans, maka $>$ Pre $\{\{\}+((V)(N)($ Adj $))=$ Benefaktif

2) Pre $\{\{\}+\mathrm{N}=\mathrm{V}>(($ Vtrans [Benefaktif] [Kausatif]) (Vintrans))

3) Pre $\{\{\}+\mathrm{Adv}=\mathrm{Adv}$

4) $\operatorname{Jika}\{\ddot{-}\}+((\mathrm{V})(\mathrm{N})(\operatorname{Adj}))=$ Vtrans, maka $>\{\ddot{-}\}+((\mathrm{V})(\mathrm{N})(\operatorname{Adj}))=$ Benefaktif

5) $\{\ddot{-}\}+((\mathrm{V})(\mathrm{N})(\mathrm{Adj}))=\mathrm{V}$

Dari hasil distribusi tersebut, terdapat satu persamaan antara prefiks $\{\{\}$ dengan geminasi $\{\ddot{-}\}$. Keduanya dapat bermakna benefaktif ketika didistribusikan pada verba, nomina, atau ajektiva.

\section{DAFTAR PUSTAKA}

Ahya, Akhmad Syauqi. 2013. Makna dan Fungsi Afiks Derivasional dalam Bahasa Arab dan Bahasa Indonesia. Malang: Madani.

Al quran Terjemah Portable. Tanpa tahun.

Anas, I.H.A. 2007. Ilmu Shorof (Morfologi Bahasa Arab). Pekalongan: Al Asri Ma'sum, Asy syaikh Muhammad bin Ali. 1965. Al amtsilah At tashrifiyyah. Maktabah as syaikh Salim bin Sa'ad Nabhan.

Munawwir, A.W. 1997. Kamus Al Munawwir Arab-Indonesia. Surabaya: Pustaka Progressif. 